\title{
Review
}

\section{The hepatorenal syndrome}

\section{Introduction}

The hepatorenal syndrome (HRS) is defined as the development of renal failure in patients with severe liver disease (acute or chronic) in the absence of any other identifiable cause of renal pathology. It is diagnosed following exclusion of other causes of renal failure in patients with liver disease such as hypovolaemia, drug nephrotoxicity, sepsis, or glomerulonephritis. A similar syndrome may also occur in the setting of acute liver failure.

DIAGNOSTIC CRITERIA

The International Ascites Club (1996) group defined the diagnostic criteria for hepatorenal syndrome ${ }^{1}$ and these are listed in table 1.

Two patterns of HRS are observed in clinical practice and these were defined by the International Ascites club. ${ }^{1}$

- Type 1 hepatorenal syndrome is an acute form of HRS in which renal failure occurs spontaneously in patients with severe liver disease and is rapidly progressive. It is characterised by marked reduction of renal function, as defined by doubling of the initial serum creatinine to a level greater than $225 \mu \mathrm{M}$, or a $50 \%$ reduction in initial 24 hour creatinine clearance to $<20 \mathrm{ml} / \mathrm{min}$ within two weeks. The development of type 1 HRS has a poor prognosis with $80 \%$ mortality at two weeks. ${ }^{2}$ Renal function may recover spontaneously following improvement in liver function. ${ }^{2}$ This is most frequently observed in acute liver failure or alcoholic hepatitis, or following acute decompensation on a background of cirrhosis. These patients are usually jaundiced with a significant coagulopathy. Death often results from a combination of hepatic and renal failure or variceal bleeding.

- Type 2 hepatorenal syndrome usually occurs in patients with diuretic resistant ascites. Renal failure has a slow course, in which it may deteriorate over months. It is associated with a poor prognosis ${ }^{3}$ although the survival time is longer than that of patients with type $1 \mathrm{HRS}$.

\section{EPIDEMIOLOGY}

HRS occurs in about $4 \%$ of patients admitted with decompensated cirrhosis, the cumulative probability being $18 \%$ at one year, increasing to $39 \%$ at five years. ${ }^{2}$ Retrospective studies indicate that HRS is present in $\sim 17 \%$ of patients admitted to hospital with ascites and in $>50 \%$ of cirrhotics

Table 1 Major criteria for a diagnosis of hepatorenal syndrome

(1) Chronic or acute liver disease with advanced hepatic failure and portal hypertension

(2) Low GFR, as indicated by serum creatinine $>225 \mu \mathrm{M}$ or creatinine clearance $<40 \mathrm{ml} / \mathrm{min}$

(3) Absence of shock, ongoing bacterial infection, or recent treatment with nephrotoxic drugs. Absence of excessive fluid losses (including gastrointestinal bleeding)

(4) No sustained improvement in renal function following expansion with 1.5 litres of isotonic saline

(5) Proteinuria $<0.5 \mathrm{~g} /$ day, and no ultrasonagraphic evidence of renal tract disease

Additional criteria NOT required for diagnosis but commonly present

(1) Urine volume $<500 \mathrm{ml} / \mathrm{day}$

(2) Urine sodium $<10 \mathrm{mM}$

(3) Urine osmolality >plasma osmolality

(4) Urine RBC $<50$ per high per field

(5) Serum sodium $<130 \mathrm{mM}$ dying from liver failure. ${ }^{3}$ The most frequent cause of renal failure in cirrhosis is spontaneous bacterial peritonitis (SBP). Approximately $30 \%$ of patients with SBP develop renal failure. ${ }^{4}$

There is still some contention as to whether patients who develop renal failure following the treatment of complications of liver diseases such as sepsis or bleeding should be classified as having HRS. Many authors include patients with "successfully treated" SBP or other precipitants as having HRS and yet there are many patients who develop renal failure spontaneously and who have no objective criteria for a precipitating event other than progressive liver failure (for example, alcoholic hepatitis or acute liver failure). In the future it may be useful to subdivide HRS type 1 into two categories - that is, those with and those without a precipitant event-but this will require further international consensus.

\section{PATHOPHYSIOLOGY}

The hallmarks of HRS are reversible renal vasoconstriction and mild systemic hypotension. ${ }^{5}$ The kidneys are structurally normal and at least in the early part of the syndrome, tubular function is intact, as reflected by avid sodium retention and oliguria. Moreover, kidneys from patients with HRS transplanted into a patient with end stage renal failure and a healthy liver resumed normal function. ${ }^{6}$

The cause of renal vasoconstriction is unknown but may involve both increased vasoconstrictor and decreased vasodilator factors acting on the renal circulation. ${ }^{7}$ There are three factors predominantly involved in its pathogenesis. These are:

(1) Haemodynamic changes that decrease renal perfusion pressure.

(2) Stimulated renal sympathetic nervous system.

(3) Increased synthesis of humoral and renal vasoactive mediators.

The emphasis of each of the three pathogenic pathways probably varies from patient to patient, and between the acute (type 1) and chronic (type 2) forms of the syndrome. Each of these pathways are interrelated and in practice the pathophysiology of this process is more complicated. However, this outline provides a simple framework with which to understand the mechanisms involved.

\section{Haemodynamic changes}

Systemic vasodilatation of varying severity is the predominant haemodynamic abnormality in portal hypertension or acute liver failure, and accounts for several important complications. ${ }^{8}$ Vasodilatation increases regional blood flow to the splanchnic circulation and a compensatory increase in cardiac output. This leads to a fall in mean arterial pressure and reflex activation of the sympathetic

Abbreviations used in this paper: HRS, hepatorenal syndrome; SBP, spontaneous bacterial peritonitis; RBF, renal blood flow; GFR, glomerular filtration rate; NO, nitric oxide; TNF, tumour necrosis factor; RAAS, renin-angiotensin-aldosterone system; NSAIDs, non-steroidal anti-inflammatory drugs; TIPS, transjugular intrahepatic portosystemic stent shunt; ET-1, endothelin 1; TXA, thromboxane $\mathrm{A}_{2}$; MARS, molecular adsorbent recirculating system; OLT, orthotopic liver transplantation. 
nervous system. ${ }^{8}$ Several studies have consistently shown a progressive decrease in mean arterial pressure with hepatic decompensation, with the lowest values (typically 60-65 $\mathrm{mm} \mathrm{Hg}$ ) observed in patients with HRS. ${ }^{9}$ Prognostic studies in patients with cirrhosis have shown that arterial pressure is one of the best predictors of survival in patients with cirrhosis and ascites, ${ }^{10}$ with low arterial pressure being associated with a poor prognosis and increased risk of developing HRS. ${ }^{11}$

It is a common misconception that modest reductions in blood pressure are insignificant in humans, and that renal autoregulation exists to prevent fluctuations in renal blood flow (RBF). However, autoregulation of the renal circulation ensures a stable $\mathrm{RBF}$ during changes in renal perfusion pressure above $70-75 \mathrm{~mm} \mathrm{Hg} .{ }^{12-14}$ Below this pressure, $\mathrm{RBF}$ is directly proportional to perfusion pressure. Patients developing HRS have an activated sympathetic system, and increased synthesis of several renal vasoconstrictors. Several studies have shown that these cause a rightward shift in the autoregulatory curve,${ }^{15}$ making RBF much more pressure dependent. Thus even modest decreases in mean blood pressure may result in a marked fall in RBF. Understanding this important principle is essential in targeting pressor treatment. As a result, there is an interest in drugs which increase blood pressure, and over the years all have been reported to increase urine output, sodium excretion, or glomerular filtration rate (GFR) with variable success in patients with severe liver disease and HRS. ${ }^{16-21}$

The presence of modest arterial hypotension raises the question about its cause. It is well established that severe liver disease is characterised by an increase in cardiac output and plasma volume, and decreased peripheral vascular resistance ${ }^{22}$ due to peripheral vasodilatation. Studies in animals and humans with cirrhosis indicate that the splanchnic circulation is the main vascular bed responsible for vasodilatation but cutaneous and muscular vascular dilatation may also contribute to the reduction in systemic vascular resistance. ${ }^{92-28}$

There is general acceptance that vascular reactivity is impaired in cirrhosis as isolated vessels have impaired responsiveness to vascular agonists. Ultimately, several mediators, either singly or in concert (nitric oxide (NO), prostacyclin, glucagon, or altered $\mathrm{K}^{+}$channel activation) may be responsible for decreased vascular reactivity or opening of these anatomical shunts. Plasma levels of many endogenous vasodilatators, as well as vasoconstrictors, are elevated in liver failure. More than one mediator may be involved, and several potential mediators have been proposed and include the following.

\section{Nitric oxide}

NO is synthesised by several cell types, including endothelial and vascular smooth muscle cells, and causes vasorelaxation. ${ }^{29} \mathrm{NO}$ synthesis may be induced by shear stress or in response to endotoxin related cytokine expression. ${ }^{30-34}$ The observation that many patients with decompensated cirrhosis have circulating endotoxaemia is thought to increase NO synthesis in cirrhosis. Studies in patients with decompensated cirrhosis show increased plasma nitrite/nitrate indicative of increased NO production. ${ }^{35}$ Pharmacological studies using isolated vascular rings or the mesenteric vasculature have shown decreased vascular reactivity to several agonists, and inhibition of $\mathrm{NO}$ synthase fully or partially restores or partially restores vascular responsiveness. ${ }^{36} 37$ Likewise, studies in vivo have shown that inhibition of NO synthesis reverses some of the systemic and splanchnic circulatory changes in animal models or patients with liver disease. ${ }^{38} 39$ This hyporeactivity is also endothelium dependent. ${ }^{40}$ Finally, NO reduces resistance in the collateral portal circulation in animals with portal hypertension. ${ }^{41}{ }^{42}$ While there was much enthusiasm for a primary role of $\mathrm{NO}$ in peripheral vasodilatation, there is still considerable controversy as to the importance of NO in the hyperdynamic circulation of cirrhosis. ${ }^{32}$

\section{Prostacyclin}

Prostacyclin is a systemic vasodilator. Its secretion might be stimulated by shear stress in the arterial system. ${ }^{30}{ }^{32}$ Urinary excretion of both systemic and renal metabolites of prostacyclin are high in decompensated cirrhosis, and plasma levels (undetectable by available analytical methods) are presumably elevated..$^{43}{ }^{44}$ Nevertheless, administration of indomethacin to cirrhotic patients increases systemic vascular resistance as well as pressor sensitivities to angiotensin II, suggesting that prostacyclin may have a facultative role in the vasodilatation of cirrhosis. ${ }^{45}$

\section{Potassium channels}

There are three major types of potassium channels which control the flux of potassium from the intracellular to the extracellular environment. The ATP sensitive potassium channels are opened during low ATP:ADP ratios, or by agonist induced activation of $G$ protein dependent pathways. The second type is the delayed rectifier channel opened by membrane depolarisation, and the third type is the calcium activated potassium channel, which is activated by increases in intracellular calcium and in a similar manner to that for ATP dependent potassium channels. Activation of potassium channels can cause vasodilatation due to hyperpolarisation of vascular smooth muscle cells. Potentially important activators include tissue hypoxia, prostacyclin, neuropeptides, and NO. Using potassium channel blockers and activators, Moreau et al found good evidence that activation of potassium channels is important in the vasodilatation of cirrhosis. ${ }^{46-48}$ Based on studies with potassium and calcium channel modifiers, Moreau and Lebrec have proposed that there is impairment of $G$ protein dependent transduction pathways. ${ }^{48}$ This hypothesis is based on the observation that hyporeactivity of vessels is not associated with downregulation of receptors, and reactivity to Bay K 8644 (which increases intracellular calcium) is normal. The central role of potassium channels in vascular tone makes it likely that potassium channels are important but whether there is a fundamental abnormality of function in a particular type of potassium channel is unknown

\section{Endotoxaemia and cytokines}

Endotoxin levels are usually elevated in patients with decompensated liver disease and more so in patients with HRS. This is believed to be due to increased bacterial translocation and portosystemic shunting. ${ }^{4-52}$ Inflammatory response to infection, as estimated by levels of cytokines in plasma or ascitic fluid, is increased in cirrhotic patients leading to circulatory dysfunction and concomitant renal impairment and increased mortality. Endotoxaemia may cause splanchnic vasodilatation, possibly mediated by cytokine induction and increased NO synthesis. Infusion of lipopolysaccharide into animals causes complement activation, accumulation of neutrophils in the liver, and renal dysfunction. There are increased circulating levels of several cytokines, including tumour necrosis factor (TNF) and interleukin 6, in patients with alcoholic hepatitis and HRS. ${ }^{33}{ }^{54}$ Recent studies have shown that the vasodilatation observed in the partial portal vein ligated rat model is blocked by anti-TNF antibodies, $\mathrm{N}$-acetylcysteine, ${ }^{55}$ and inhibitors of tyrosine kinase, each of which may act on cytokine dependent pathways. ${ }^{567}$ 
Table 2 Consequences of systemic vasodilatation

- Activation of the sympathetic nervous system

- Activation of the renin-angiotensin-aldosterone system

- Ancreased vasopressin release

- Increased renal production of vasodilatory prostanoids

\section{Glucagon}

Plasma glucagon levels are elevated in cirrhosis. Glucagon causes desensitisation of the mesenteric circulation to catecholamines and angiotensin II, and causes vasodilatation at pharmacological doses. ${ }^{58}$ Glucagon also elevates intracellular cAMP and this may act synergistically with endotoxin to induce NO synthase, and thus NO release by vascular smooth muscle cells. ${ }^{59}$ Hence glucagon may enhance NO production in cirrhosis.

SECONDARY CONSEQUENCES OF SYSTEMIC VASODILATATION The normal homoeostatic response to vasodilatation is activation of several neurohumoral response mechanisms, primarily aimed at maintenance of arterial pressure. These responses are summarised in table 2 :

Although activation of these neurohumoral mechanisms help to maintain blood pressure, some also induce renal vasoconstriction. This is not surprising as the renal vascular bed normally receives $25 \%$ of cardiac output and is an important regulatory pivot of blood pressure. By altering the normal renal autoregulatory response, they by necessity contribute to decreased RBF observed in HRS.

Renin-angiotensin-aldosterone system (RAAS)

The RAAS is stimulated in $50-80 \%$ of patients with decompensated cirrhosis, and is further activated in patients with HRS. ${ }^{22} 576061$ Increased levels of angiotensin II protect renal function by selective vasoconstriction of the efferent glomerular arterioles. Although $\mathrm{RBF}^{62}$ may fall, GFR is preserved due to an increased filtration fraction. In cirrhosis, inhibition of the RAAS by either angiotensin II antagonists or angiotensin converting enzyme inhibitors (for example, captopril) may cause marked hypotension and a decrease in $\mathrm{GFR}^{63-67}$ and conversely, infusion of angiotensin II in cirrhosis improves GFR in some patients. ${ }^{62}$ Angiotensin II helps to maintain vascular tone in patients with advanced liver disease but has no role in healthy controls or patients with compensated cirrhosis. A recent finding that losartan (an angiotensin II receptor antagonist) decreases portal pressure in patients with cirrhosis and portal hypertension ${ }^{68-70}$ together with the vascular dependence on angiotensin II in severe cirrhosis, indicates that this mediator contributes to vascular dysfunction in cirrhosis.

\section{Antidiuretic hormone}

Antidiuretic hormone or vasopressin levels are elevated due to non-osmolar stimulation, despite the frequent presence of hyponatraemia. ${ }^{71}$ Vasopressin causes vasoconstriction through $V_{1}$ receptors and renal tubular water retention through $\mathrm{V}_{2}$ receptors in the medullary collecting ducts. This increases volume expansion by water retention and helps maintain arterial pressure. Inhibition of $\mathrm{V}_{1}$ receptors in cirrhotic rats causes profound hypotension. ${ }^{73}$ Vasopressin however preferentially causes splanchnic rather than renal vasoconstriction.

\section{Prostaglandins}

Renal prostaglandins play an important role in the preservation of renal function in all situations, such as dehydration, congestive cardiac failure, shock, or decompensated liver disease, with elevated plasma levels of renin, angiotensin, noradrenaline, or vasopressin. In liver disease, urinary excretion of prostaglandin $\mathrm{E}_{2}$ and prostacyclin metabolites (6-oxo-PGF ${ }_{10}$ ) are usually increased. ${ }^{44}{ }^{74-78}$ The mechanism for increased synthesis is unknown but is likely to be secondary to increased levels of several vasoconstrictors which induce prostaglandin formation in vitro or in vivo. Administration of cyclooxygenase inhibitors (nonsteroidal anti-inflammatory drugs (NSAIDs)) to patients with ascites frequently causes renal failure, and this usually reverses on cessation of NSAIDs ${ }^{78}$ (see fig 1 ).$^{79}$ It has been suggested that HRS is caused by a deficiency in renal prostaglandin $\mathrm{E}_{2}$ and prostacyclin ${ }^{78}$ as urinary excretion of prostaglandin $\mathrm{E}_{2}$ and the prostacyclin metabolite 6-oxo$\mathrm{PGF}_{1 \alpha}$ are decreased in HRS compared with patients with ascites alone. Other studies however have shown that synthesis of prostacyclin is actually increased but urinary excretion of its metabolite is decreased by the presence of renal failure. ${ }^{44}$ The importance of each of these compensatory mechanisms is indicated by the fact that inhibition or antagonism of their actions frequently has adverse effects on systemic or renal function. Thus although they may contribute to some or many of the renal haemodynamic changes, the overall result of their activation tends to be beneficial.

\section{The sympathetic nervous system}

The sympathetic nervous system is highly activated in patients with HRS and causes renal vasoconstriction and increases sodium retention. ${ }^{80-83}$ Several studies have shown that there is increased secretion of catecholamines in the renal and splanchnic vascular beds. ${ }^{84-86}$

The importance of hepatorenal innervation has been recognised since the 1980 s. Kostreva and colleagues ${ }^{87}$ observed that an increase in intrahepatic pressure resulted in greater efferent renal sympathoadrenergic activity. Vasoconstriction of the afferent arterioles of the kidney led to a reduction in renal plasma flow and GFR and to increased reabsorbtion of tubular sodium and water. Hepatic denervation was effective in delaying, but not preventing, the increased tubular reabsorption of sodium in portal hypertension, and Levy and Wexler ${ }^{88}$ discovered that the onset of ascites formation was delayed in dogs with bile duct ligation following hepatic denervation. This concept has been reintroduced by Lang and colleagues ${ }^{89}$ who observed that infusion of glutamine into the internal jugular vein had no effect on renal function whereas it caused a significant decrease in both GFR and RBF when infused into the portal vein. The mechanism is postulated to be secondary to hepatocyte swelling and activation of the renal sympathetic nervous system as no effect was seen in those animals with renal denervation. In support of this concept in humans, studies by Jalan et al have shown that acute occlusion of the transjugular intrahepatic portosystemic stent shunt (TIPS) is associated with an acute reduction in RBF in patients with cirrhosis. ${ }^{90}$ In another study, temporary lumbar sympathectomy with local anaesthesia increased GFR in five of eight cirrhotic patients with HRS, ${ }^{11}$ suggesting that increased renal sympathetic nervous activity decreased GFR in some patients.

\section{Humoral and renal vasoactive mediators}

It is unlikely that development of HRS is purely a consequence of renal vasoconstriction. If one examines the relationship between $\mathrm{RBF}$ and the presence of HRS or hepatic decompensation with or without ascites, there is considerable overlap of RBF between these groups (fig 2). ${ }^{92}$

The observation that two patients may have a comparable decrease in RBF and yet have either HRS or "near normal renal function" suggests that other factors must be involved which decrease the filtration fraction. The glomeruli within the kidney are dynamic structures, 


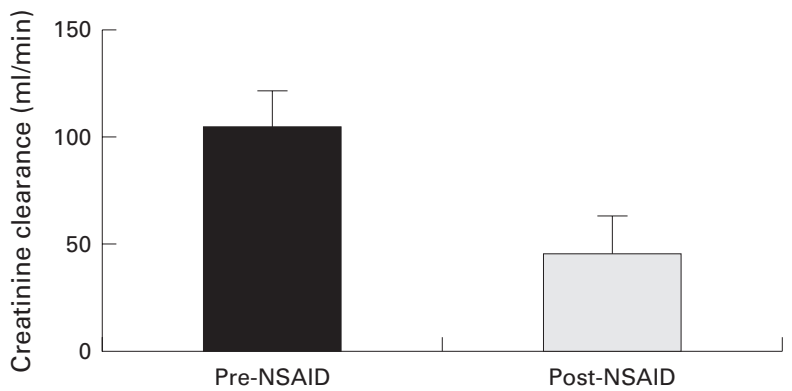

Figure 1 Administration of indomethacin, a non-steroidal anti-inflammatory drug (NSAID), to patients with cirrhosis AND ascites, caused a significant reduction in renal plasma flow (not shown) and glomerular filtration rate, as assessed by creatinine clearance (adapted from Boyer and colleagues ${ }^{79}$ ).

invaginated with mesangial cells which may contract in response to several agonists and thus reduce the surface area available for glomerular filtration (fig 2). Many studies have now shown that there is increased synthesis of several vasoactive mediators, which although renal vasoconstrictors in their own right, also have the important added effect of causing mesangial cell contraction, thence lowering the glomerular capillary ultrafiltration coefficient $\left(\mathrm{K}_{\mathrm{f}}\right)$ and thus the filtration fraction. Such factors involved may include the following.

\section{Endothelin}

This 21 amino acid peptide is a potent renal vasoconstrictor and a potent agonist of mesangial cell contraction. Endothelin 1 (ET-1) concentrations are increased in HRS and correlate with creatinine clearance in decompensated liver disease. ${ }^{93-95}$ Brensing and colleagues $^{96}$ noted a reduction in portal ET-1 levels after TIPS placement while systemic levels remained unchanged. Both observations indicate that local ET-1 formation may be more relevant in kidney dysfunction in HRS than circulating ET-1. The cause of increased plasma ET-1 concentrations is unknown. Volume expansion or upright tilt fails to increase plasma endothelin in cirrhotics ${ }^{97}$ and there appears to be no correlation with circulating endotoxins. ${ }^{98}$ Whether tissue hypoxia or oxidant stress dependent pathways are important are unknown. Increased lipid peroxidation is known to occur in HRS, ${ }^{99}$ and certain products of lipid peroxidation, namely oxidised low density lipoprotein and $\mathrm{F}_{2}$ isoprostanes, have been shown to induce ET-1 synthesis in vitro, ${ }^{100}$

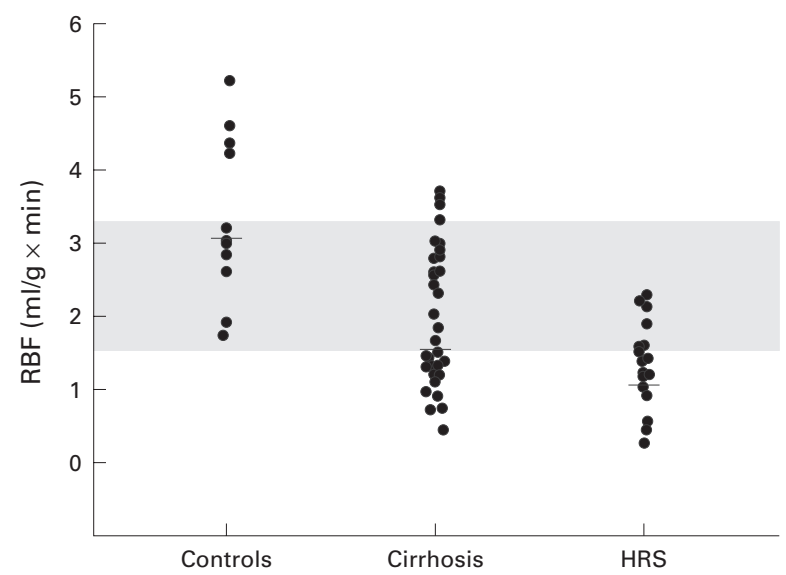

Figure 2 Measurement of renal blood flow (RBF) by 133-xenon washout shows that $R B F$ is decreased in cirrhosis and further decreased in patients with hepatorenal syndrome (HRS). However, as is evident in the shaded area, there is a considerable overlap in $R B F$ values between normal, cirrhotic, and HRS patients (adapted from Ring-Larsen $H$. Renal blood flow in relation to systemic and portal haemodynamics and liver function. Scand $\mathcal{F}$ Clin Lab Invest 1977;37:635-42). but whether this is responsible for increased plasma ET-1 concentrations is unknown.

Cysteinyl leukotrienes

Leukotrienes $\mathrm{C}_{4}$ and $\mathrm{D}_{4}$ are produced by inflammatory cells of the myeloid series, and their synthesis by the isolated kidney has been demonstrated. ${ }^{101}$ They are both potent renal vasoconstrictors and cause contraction of mesangial cells in vitro. Endotoxaemia, activation of complement, or various cytokines may stimulate their synthesis. There is good evidence that systemic and probably renal synthesis of cysteinyl leukotrienes is increased in HRS. Urinary leukotriene $\mathrm{E}_{4}$ is markedly elevated as well as $\mathrm{N}$-acetyl $\mathrm{LTE}_{4}$ in HRS. ${ }^{102-104}$ Plasma concentrations are too low to have a direct effect on the renal circulation but renal leukotriene synthesis may be an important modulator of renal function in HRS.

Thromboxane $A_{2}$

Thromboxane $\mathrm{A}_{2}$ ( $\mathrm{TXA}_{2}$ ) production is stimulated by renal ischaemia and causes both vasoconstriction and mesangial cell contraction. It has been suggested that the balance between vasodilatory prostaglandins and thromboxane $\mathrm{A}_{2}$ may critically favour vasoconstriction. ${ }^{105}{ }^{106}$ However, many of the early studies used urinary excretion of prostaglandin metabolites as markers of renal production, and failed to control for renal function or the severity of liver disease. It is now known that $\mathrm{TXB}_{2}$ excretion should be corrected for renal function, and when this is done it has been shown that urinary $\mathrm{TXB}_{2}$ excretion correlates with the severity of liver disease, rather than the presence or absence of renal failure. Furthermore, inhibition of $\mathrm{TXA}_{2}$ synthesis with dazoxiben does not improve renal function. ${ }^{106}$

\section{$F_{2}$ isoprostanes}

The $\mathrm{F}_{2}$ isoprostanes are formed by lipid peroxidation. One of the major $\mathrm{F}_{2}$ isoprostanes formed in vivo, namely 8-iso$\mathrm{PGF}_{2}$, is a potent renal vasoconstrictor. We have observed increased synthesis of the $\mathrm{F}_{2}$ isoprostanes in patients with HRS indicative of increased lipid peroxidation. ${ }^{99}$ Whether $\mathrm{F}_{2}$ isoprostanes themselves are important mediators of renal vasoconstriction in HRS is unknown. However, synthesis of several mediators implicated in the pathogenesis of HRS are regulated through products of lipid peroxidation or through redox changes in signalling pathways. Thus the development of oxidant stress may be important as the final pathway leading to increased synthesis of many of the mediators discussed above.

\section{Management of the hepatorenal syndrome}

PREVENTION

The following measures may decrease the incidence of renal failure or HRS in patients with liver disease.

Prophylaxis against bacterial infections

Bacterial infections occur in $~ 50 \%$ of patients with variceal haemorrhage, and antibiotic prophylaxis improves survival by $\sim 10 \%$. Patients who have had a previous episode of SBP have an $68 \%{ }^{107}$ chance of recurrent infection at one year, and this carries a $33 \%$ chance of developing renal failure. ${ }^{108}$ As bacterial infections are an important cause of renal dysfunction in cirrhotic patients, prophylaxis with antibiotics is recommended in two clinical settings, namely variceal bleeding and a history of previous SBP.

\section{Volume expansion}

To prevent the development of renal failure in patients who develop SBP, it is now recommended that these patients should be given plasma volume expansion with $20 \%$ albu$\mathrm{min}(1-1.5 \mathrm{~g} / \mathrm{kg}$ over $1-3$ days) at diagnosis to prevent circulatory dysfunction, renal impairment, and mortality. ${ }^{109}$ 


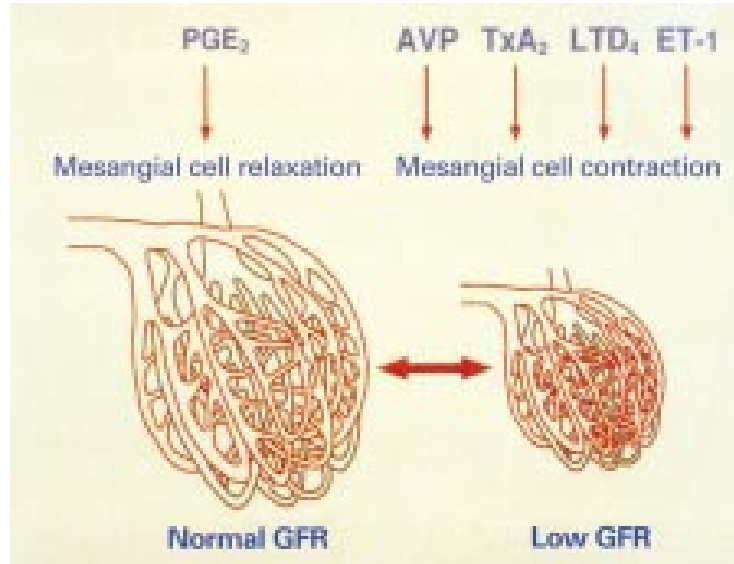

Figure 3 The glomeruli within the kidney are dynamic structures, invaginated with mesangial cells which express actin. These contractile cells control the surface area of glomeruli available for filtration. The cells contract in response to certain agonists such as endothelin 1 (ET-1), thromboxane $A_{2}\left(T X A_{2}\right)$, arginine vasopressin $(A V P)$, or leukotriene D4 $\left(\mathrm{LTD}_{4}\right)$. Vasodilatory prostaglandins such prostaglandin $\mathrm{E}_{2}\left(\mathrm{PGE}_{2}\right)$ can cause relaxation of mesangial cells.

Use of salt poor albumin as fluid replacement in patients undergoing large volume paracentesis ( $8 \mathrm{~g}$ for each litre of ascitic fluid removed) is known to prevent paracentesis induced circulatory dysfunction. ${ }^{110-112}$

\section{Fudicious use of diuretics}

Identifying the lowest effective dose of a diuretic for any individual patient is important, as diuretic induced renal impairment occurs in $\sim 20 \%$ of patients with ascites. It develops when the rate of diuresis exceeds the rate of ascites reabsorption, leading to intravascular volume depletion. Diuretic induced renal impairment is usually moderate and rapidly reversible following diuretic withdrawal.

Avoid use of nephrotoxic drugs

Patients with cirrhosis and ascites are predisposed to develop acute tubular necrosis during use of aminoglycosides, with renal failure occurring is $\sim 33 \%$ of patients compared with $3-5 \%$ in the general population. ${ }^{113}$ Another important cause of renal failure is the use of NSAIDs. These drugs inhibit formation of intrarenal prostaglandins causing a marked decline in renal function and $\mathrm{Na}^{+} / \mathrm{H}_{2} \mathrm{O}_{2}$ excretion in cirrhotic patients with ascites (fig 1).

\section{Treatment of hepatorenal syndrome}

\section{INITIAL MANAGEMENT}

- Optimal fluid management: renal function rarely recovers in the absence of hepatic recovery. The key goal in the management of these patients is to exclude reversible or treatable lesions (mainly hypovolaemia), and to support the patient until liver recovery (for example, from alcoholic hepatitis), hepatic regeneration (acute liver disease), or liver transplantation. The treatment of HRS is directed towards reversing the haemodynamic changes induced by reduced renal perfusion pressure, stimulated sympathetic nervous system, and increased synthesis of humoral and renal vasoconstrictor factors.

- In cirrhotic patients, renal insufficiency is frequently secondary to hypovolaemia (diuretics or gastrointestinal bleeding), NSAIDs, or sepsis. Precipitating factors should be recognised and treated, and nephrotoxic drugs discontinued.

- All patients should be challenged with up to 1.5 litres of fluid such as human albumin solution or normal saline to assess the renal response as many patients with subclinical hypovolaemia will respond to this simple measure. This should be done with careful monitoring to avoid fluid overload. In practice, fluid overload is not usually a problem as patients with severe liver disease act as "fluid sumps" and their vasculature adapts to accommodate the extra fluid. This has been confirmed by Hadengue et al who described increased venous compliance following fluid challenge in advanced cirrhosis. ${ }^{114}$ Two recent studies have shown that prolonged treatment of patients with HRS (two weeks) with albumin and systemic vasoconstrictors (ornipressin ${ }^{115}$ or terlipressin ${ }^{116}$ ) resulted in an improvement in renal function in HRS.

- Evidence of sepsis should be sought by blood, ascitic, cannulae, and urine culture, and non-nephrotoxic broad spectrum antibiotics commenced, regardless of evidence of sepsis, as an undiagnosed delay in effective treatment of infection may increase mortality. In advanced cirrhosis, endotoxins and cytokines play increasingly important roles in advancing the hyperdynamic circulation and worsening renal function. ${ }^{117}$

\section{OPTIMISATION OF RENAL HAEMODYNAMICS}

\section{Optimise blood pressure}

If mean arterial pressure is low ( $<70 \mathrm{~mm} \mathrm{Hg}$ ), it should be increased to approximately $85-90 \mathrm{~mm} \mathrm{Hg}$ or until urine output improves by infusing a vasopressor drug. Vasopressin, ornipressin, terlipressin, or noradrenaline infusion have all been used with some success. ${ }^{2362118}$ On physiological grounds it seems sensible to use either ornipressin or terlipressin as firstline.

\section{Paracentesis}

Drainage of tense ascites may temporarily improve renal haemodynamics and renal function by decreasing renal venous pressure. There may be a modest fall in blood pressure following paracentesis. There is no evidence to support this approach although it seems logical on the basis of published data. The fall in renal perfusion pressure due to decreased arterial pressure may of course counteract any beneficial effect and should therefore be counterbalanced by pressor support, as necessary.

\section{Pharmacological treatment}

All of the drugs that have been investigated in HRS have one overriding aim-to increase RBF. This has been either indirectly, by splanchnic vasoconstriction, or directly using renal vasodilatators. One of the principle difficulties has been the lack of agents which act purely on the splanchnic circulation. Drugs which "spill over" into the systemic circulation may actually exacerbate the intense renal vasoconstriction already present. Currently, there is significant enthusiasm for vasoconstrictor agents in HRS. However, the numbers of patients studied has been small, mortality remains high, and there have been no randomised placebo controlled trials. This clearly needs to be addressed but is limited to the relative rarity of pure HRS patients without confounding variables such as sepsis and gastrointestinal bleeding. An important aspect of these reports is the need for a pressor response to these agents as well as return of abnormal renal function after cessation of vasoconstrictor therapy. HRS is effectively a marker of poor hepatic function, and these agents are probably best utilised as a bridge to further improvement in liver function, either following cessation of alcohol or liver transplantation. Thus the decision to use vasoconstrictor agents for HRS should be based on whether the patient is a realistic transplant candidate or if not, whether liver function might improve. Patients who do not satisfy these criteria will be treated unnecessarily, merely prolonging the 
process of dying, at a time when palliative care would be more appropriate.

Dopamine. Dopamine was the first drug used due its vasodilator effect when given in subpressor doses. Dopamine is frequently prescribed to patients with renal impairment, and yet no studies have ever shown any convincing benefit. ${ }^{119}{ }^{120}$ It is our impression that occasionally ( $<5 \%$ of the time) a patient responds with an increase in urine output. It is therefore our practice to give a 12 hour trial of dopamine and stop treatment if there is no improvement in urine output.

Ornipressin. Ornipressin is a vasopressin analogue that preferentially causes vasoconstriction of the splanchnic vasculature thus increasing blood and renal perfusion pressure. These effects are reflected by a commensurate decrease in plasma renin and angiotensin, and improved renal clearance and sodium excretion. ${ }^{121}$ In 1996 , Salo and colleagues $^{120}$ studied 20 patients with hepatorenal syndrome. A two hour infusion of ornipressin at $6 \mathrm{IU} / \mathrm{h}$ in 11 patients resulted in a significant fall in plasma renin and a rise in blood pressure. In the same 11 patients, addition of dopamine with ornipressin had no further benefit. In the second part of their protocol performed on a further five patients, intravenous infusion of noradrenaline plus prostacyclin failed to increase renal perfusion or glomerular filtration rate, and actually reduced urinary volume and sodium excretion. In 1998, Guevara and colleagues ${ }^{115}$ also examined the role of ornipressin in the management of HRS. Two protocols were employed: each was performed in a group of eight patients. Using a combination of ornipressin and albumin infusion, they observed that prolonged administration of the combination resulted in an increase in mean arterial pressure and normalisation of renal function. These improvements were reflected by a marked fall in plasma renin activity, plasma aldosterone, noradrenaline concentrations, and an increase in atrial natriuretic peptide. HRS did not recur after cessation of therapy in patients who finished the 15 day treatment despite a rebound increase in the activity of systemic vasoconstrictor factors. However, this treatment had significant complications. Four patients had to stop therapy after six days because of serious side effects, including ischaemic colitis, an infarcted tongue, asymptomatic ventricular extrasystoles, and bacteraemia due to a urinary tract infection.

Terlipressin. Terlipressin (glypressin) is a synthetic analogue of vasopressin with intrinsic vasoconstrictor activity. It is slowly cleaved in vivo into vasopressin by enzymatic cleavage of the triglycyl residue. It has the advantage over vasopressin of a longer biological half life allowing administration as a four hourly bolus. Hadengue and colleagues ${ }^{122}$ showed that two day terlipressin administration ( $2 \mathrm{mg} /$ day) increased blood pressure, GFR, and urine output in nine patients with type $1 \mathrm{HRS}$ in a placebo controlled crossover study. No side effects were reported. These results were also confirmed by Uriz et al who showed that longer term administration of terlipressin with albumin for two weeks reversed HRS in seven of nine patients. ${ }^{116}$

Midodrine and octreotide. Octreotide is a long acting analogue of somatostatin which has a variable effect on splanchnic haemodynamics. Midodrine is a sympathomimetic drug. Data on its use in HRS are limited to a recent publication by Angeli and colleagues ${ }^{123}$ and a series from Kaffy and colleagues. ${ }^{21}$ Angeli and colleagues ${ }^{123}$ demonstrated that combined long term administration of midodrine, an oral $\alpha$ adrenergic agent, and octreotide, led to improvement in renal function. After 20 days of treatment with midodrine and octreotide, an impressive improvement in renal plasma flow, GFR, and urinary sodium excretion was observed. This was accompanied by a significant reduction in plasma renin activity, plasma vasopressin, and plasma glucagon. No side effects were observed.

Misoprostol. Misoprostol, a synthetic analogue of prostaglandin E1, was examined by Fevery et al in $1990^{124}$ in four patients with HRS at a dose of $0.4 \mathrm{mg}$ four times daily, orally. All four patients responded with diuresis and a fall in creatinine although only two patients had natriuresis. In a larger study by Gines and colleagues, ${ }^{125}$ nine patients with renal impairment with or without hyponatraemia but not fulfilling the criteria for HRS, were given $0.2 \mathrm{mg}$ misoprostol four times daily for four days. No changes in GFR (59 (11) $v 54(11) \mathrm{ml} / \mathrm{min}$ ), sodium excretion (4.0 (1.3) $v 4.1$ (2) $\mu \mathrm{Eq} / \mathrm{min})$, or free water clearance $(2.4(0.8) v 2.1(0.9)$ $\mathrm{ml} / \mathrm{min}$ ) were observed. An infusion of prostaglandin $\mathrm{E}_{2}$ in a similar group of nine patients had a similarly disappointing lack of effect on GFR and sodium excretion, and decreased free water clearance.

Endothelin antagonists. Endothelin, a potent endogenous vasoconstrictor, is increased in patients with HRS. ${ }^{126}$ The role of an $\mathrm{ET}_{\mathrm{A}}$ antagonist $\mathrm{BQ} 123$ was examined in a preliminary study of three cirrhotic patients with HRS by Soper and colleagues. ${ }^{127}$ Consecutive 10, 25, and 100 $\mathrm{nmol} / \mathrm{min}$ infusions of BQ123 were given for 60 minutes. All three patients showed a dose-response improvement in inulin and para-amino hippuric acid clearance, approaching $100 \%$ at the highest dose. All three patients subsequently died.

$N$-Acetylcysteine. There has been one series of 12 patients (nine of whom had alcoholic cirrhosis) with HRS where $\mathrm{N}$-acetylcysteine was given intravenously for five days. This treatment was well tolerated with no side effects. At baseline, following aggressive fluid replacement, mean creatinine clearance was 24 (3) $\mathrm{ml} / \mathrm{min}$, rising to 43 (4) $\mathrm{ml} / \mathrm{min}$ following five days of therapy. This was associated with an increase in urine output, and a significant increase in sodium excretion from $1.2(0.5)$ to $1.8(0.6) \mathrm{mmol} / \mathrm{h}$ $(p<0.05)$. High survival values of $67 \%(8 / 12)$ at one month and $58 \%(7 / 12)$ at three months were observed. This included two patients who underwent successful liver transplantation after improvement in renal function. ${ }^{128}$

RENAL SUPPORT

Renal support should only be given when there is a clear goal of management and potential outcome. Thus renal support should only be offered where there is a realistic possibility of hepatic regeneration, hepatic recovery, or liver transplantation. Renal support otherwise merely prolongs the dying process. Renal support is generally given as continuous haemofiltration. Intermittent haemodialysis causes marked haemodynamic instability in some patients. The molecular adsorbent recirculating system (MARS) is a modified dialysis method using albumin containing dialysate that is recirculated and perfused online through charcoal and anion exchanger columns. MARS enables the elective removal of albumin bound substances. Mitzner and colleagues, ${ }^{129}$ in a randomised controlled trial, compared standard therapy consisting of volume expansion, dopamine, and haemodynamic filtration versus the same plus extracorporeal albumin dialysis. They found a significant improvement in standard liver and kidney test function in the MARS group. Mortality rates where $100 \%$ in the control group and $62.5 \%$ in the MARS group at day 7. Further studies are underway.

\section{Surgical manoeuvers, TIPS, and liver transplantation}

There are few case reports of TIPS in patients with HRS and results are mixed. Some patients have a delayed 
response (after four weeks) with improvement in renal function, and some worsen. In other words, patients can do very well if they survive the procedure but some develop significant complications, particularly when the patient has a Child Pugh score for severity of liver disease greater than 12. Only prospective randomised studies can resolve this issue. However, the largest series show improvement in renal function in most patients with type 2 HRS. The German series ${ }^{130}$ had six of 16 patients with type 1 syndrome. Three month survival was $75 \%$. Recently, long term follow up of this group with a larger cohort (median follow up two years) has been published. ${ }^{96}$ Thirty one patients with HRS received TIPS (14 patients with HRS type 1, 17 with HRS type 2). Following TIPS, total survival rates at three and 12 months were $63 \%$ and $39 \%$, respectively. These results are encouraging but controlled trials are required to confirm improvement in prognosis. TIPS could serve as a bridge to liver transplantation allowing kidney function to recover and clinical status to improve.

The only effective and permanent treatment for HRS is orthotopic liver transplantation (OLT). Gonwa et al compared survival following OLT of 56 patients with HRS with 513 controls (non HRS). They observed one and four year survival rates of $71 \%$ and $60 \%$, respectively, for HRS patients, and $83 \%$ and $70 \%$ for non-HRS patients. ${ }^{131}$ The same retrospective study also considered the long term evolution of renal function following OLT for both groups of patients. Both cyclosporin and FK506 (used following OLT) also impaired renal function. As a consequence, in 407 non-HRS patients, GFR decreased from 94 to 60 $\mathrm{ml} / \mathrm{min}$ at one year following transplantation. In 34 patients with HRS, GFR increased from 14 to $44 \mathrm{ml} / \mathrm{min}$ at one year following transplantation..$^{13}$ Preoperative and postoperative morbidity in HRS patients was higher. Dialysis was required in $32 \%$ of HRS patients prior to OLT and $10 \%$ remained on dialysis following transplantation. Overall mean post-transplant hospital stay was 42 days for patients with HRS compared with 27 days for those without HRS. ${ }^{131}$ Hence it seems clear that eligible patients with HRS can safely benefit from liver replacement at the price of increased time spent in hospital and modest impact on long term survival. ${ }^{132}$

\section{Conclusion}

The hepatorenal syndrome is a syndrome of functional renal failure due to end stage liver disease. It is caused by impaired renal perfusion pressure, stimulation of the renal sympathetic nervous system, and production of mediators causing mesangial contraction and reduced filtration fraction. Patients with HRS should be treated by supportive measures (blood pressure support and antibiotics), and haemofiltration of dialysis only given if recovery of liver function is likely, either spontaneously or following liver transplantation.

L DAGHER K MOORE

Centre for Hepatology,

Royal Free and University College Medical School,

London NW3 2PF, UK

Correspondence to: K Moore, Centre for Hepatology, Royal Free and University College Medical School, Rowland Hill St, London NW3 2PF, UK. kmoore@rfc.ucl.ac.uk

1 Arroyo V, Gines P, Gerbes AL, et al. Definition and diagnostic criteria of refractory ascites and hepatorenal syndrome in cirrhosis. Hepatology 1996;23:164-76.

2 Gines A, Escorsell A, Gines P, et al. Incidence, predictive factors, and prognosis of the hepatorenal syndrome in cirrhosis with ascites. Gastroenterology 1993;105:229-36.

3 Arroyo V, Gines P, Jimenez V, et al. Renal dysfunction in cirrhosis. In: Bircher J, Benhamou J-P, McIntyre N, et al, eds. Oxford textbook of clinical hepatology. Oxford: Oxford University Press, 1999;733-61.
4 Gines P, Martin P-Y, Niederberger M. Prognostic significance of renal dysfunction in cirrhosis. Kidney Int Suppl 1997;51:S77-82.

5 Schrier RW, Arroyo V, Bernardi M, et al. Peripheral arterial vasodilation hypothesis: A proposal for the initiation of renal sodium and water retention in cirrhosis. Hepatology 1988;8:1151-7.

6 Koppel MH, Coburn JM, Mims MM, et al. Transplantation of cadaveric kidneys from patients with hepatorenal syndrome. Evidence for the functional nature of renal failure in advanced liver disease. $N \mathrm{Engl} f \mathrm{Med}$ 1969;280:1367-71.

7 Moore K. The hepatorenal syndrome. Clin Sci 1997;92:433-43.

8 Colombato L, Albillos A, Groszmann RJ. Temporal relationship of peripheral vasodilation, plasma volume expansion and the hyperdynamic circulatory state in portal-hypertensive rats. Hepatology 1991;15:323-8.

9 Fernanadez-Seara J, Prieto J, Quiroga J, et al. Systemic and regional hemodynamics in patients with liver cirrhosis ans ascites with and without functional renal failure. Gastroenterology 1989;97:1304-12.

10 Llach J, Gines J, Arroyo V, et al. Prognostic value of arterial pressure, endogenous vasoactive systems, and renal function in cirrhotic patients admitted enous vasoactive systems, and renal function in cirrhotic patients admitted

11 Gines A, Escorsell A, Gines P, et al. Incidence, predictive factors and prognosis of the hepatorenal syndrome in cirrhosis with ascites. Gastroenterology 1993;105:229-36.

12 Selkurt E. The relation of renal blood flow to effective arterial pressure in the intact kidney of the dog. Am F Physiol 1946;147:537-49.

13 Navar LG. Renal autoregulation: perspectives from whole kidney and single nephron studies. Am F Physiol 1978;234:357-70.

14 Stein J. Regulation of the renal circulation. Kidney Int 1990;38:571-6.

15 Person PB, Ehmeke H, Naf B, et al. Sympathetic modulation of renal autoregulation by carotid occlusion in conscious dogs. Am f Physiol 1990; 258:F364-70.

16 Dagher L, Patch D, Marley R, et al. Pharmacological treatment of the hepatorenal syndrome in cirrhotic patients. Aliment Pharmacol Ther 2000;14 515-21.

17 Cervoni J-P, Lecomte T, Cellier C, et al. Terlipressin may influence the outcome of hepatorenal syndrome complicating alcoholic hepatitis. Am $\mathcal{F}$ Gastroenterol 1997;92:2113-14.

18 Evrard P, Ruedin P, Installe E, et al. Low-dose ornipressin improves renal function in the hepatorenal syndrome. Crit Care Med 1994;22:363-6.

19 Ganne-Carri N, Hadengue A, Mathurin P, et al. Hepatorenal syndrome: Long-term treatment with terlipressin as a bridge to liver transplantation. Dig Dis Sci 1996;41:1054-6.

20 Hadengue A, Gadano A, Moreau R, et al. Beneficial effects of the 2 day administration of terlipressin in patients with cirrhosis and hepatorenal syndrome. I Hepatol 1998;29:565-70.

21 Kaffy F, Borderie C, Chagneau C, et al. Octreotide in the treatment of the hepatorenal syndrome in cirrhotic patients [2]. F Hepatol 1999;30:174.

22 Schrier R, Arroyo V, Bernardi M, et al. Peripheral vasodilation hypothesis. A proposal for the initiation of renal sodium and water retention in cirrhosis. Hepatology 1988;8:1151-7.

23 Lancestermere RG, Davidson PL, O'Brien FJ, et al. Renal failure in Laennec's cirrhosis. II. Simultaneous determination of cardiac output and renal hemodynamics. F Clin Invest 1962;41:1922-7.

24 Maroto A, Gines P, Arroyo V, et al. Brachial and femoral artery blood flow in cirrhosis: relationship to kidney dysfunction. Hepatology 1993;17:78893.

25 Wong F, Logan A, Blendis L. Hyperinsulinemia in preascitic cirrhosis: Effects on systemic and renal hemodynamics, sodium homeostasis, forearm blood flow and sympathetic nervous activity. Hepatology 1996;23:414-22.

26 Mitamura K, Kawauchi A, Sasaki K, et al. Measurement of renal artery blood flow velocity by Doppler ultrasonography in chronic liver disease. Hepatol Res 1999;15:201-14.

27 Sato S, Ohnishi K, Sugita S, et al. Splenic artery and superior mesenteric artery blood flow: nonsurgical Doppler US measurement in healthy subjects and patients with chronic liver disease. Radiology 1987;164:34752.

28 Bernardi M, Trevisani F. Systemic and regional hemodynamics in preascitic cirrhosis. F Hepatol 1997;27:588-91.

29 Vallance P, Moncada S. Hyperdynamic circulation in cirrhosis: a role for nitric oxide? Lancet 1991;337:776-8

30 Hecker M, Mülsch A, Bassenge E, et al. Vasoconstriction and increased flow: two principle mechanisms of shear stress-dependent endothelial autacoid release. Am 7 Physiol 1993;265:H828-33.

31 Stark ME, Szurszewski JH. Role of nitric oxide in gastrointestinal and hepatic function and disease. Gastroenterology 1992;103:1928-49.

32 Bomzon A, Blendis LM. The nitric oxide hypothesis and the hyperdynamic circulation in cirrhosis. Hepatology 1994;20:1343-50.

33 Groszmann RJ. Hyperdynamic circulation of liver disease 40 years later: pathophysiology and clinical consequences. Hepatology 1994;20:1359-63.

34 Pierre-Yves $M$, Gines $P$, Schrier R. Nitric oxide as a mediator of hemodynamic abnormalities and sodium and water retention in cirrhosis. N Engl F Med 1998;339:533-41.

35 Guarner C, Soriano G, Tomas A, et al. Increased serum nitrite and nitrate levels in patients with cirrhosis: relationship to endotoxemia. Hepatology 1993;18:1139-43.

36 Claria J, Jimenez W, Ros J, et al. Increased nitric oxide dependent vasorelaxation in aortic rings of cirrhotic rats with ascites. Hepatology 1994; 20:1615-21.

37 Mathie RT, Ralevic V, Moore KP, et al. Mesenteric vasodilator responses in cirrhotic rats: A role for nitric oxide? Hepatology 1996;23:130-6.

38 Pizcueta MP, Pique JM, Fernandez M, et al. Modulation of the hyperdynamic circulation of cirrhotic rats by nitric oxide inhibition. Gastroenterology 1992;103:1909-15.

39 Forrest EH, Jones AL, Dillon JF, et al. The effect of nitric oxide synthase inhibition on portal pressure and azygous blood flow in patients with cirrhosis. F Hepatol 1995;23:254-8.

40 Atucha NM, Shah V, Garcia-Cardena G, et al. Role of endothelium in the abnormal response of mesenteric vessels in rats with portal hypertension and liver cirrhosis. Gastroenterology 1996;111:1627-32.

41 Lee F-Y, Colombato LA, Albillos A, et al. Administration of N-nitro-Larginine ameliorates portal-systemic shunting in portal-hypertensive rats. Gastroenterology 1993;105:1464-70.

42 Mosca P, Lee F-Y, Kaumann AJ, et al. Pharmacology of portal-systemic collaterals in portal hypertensive rats: role of endothelium. Am F Physiol 1992; 263: G544-50 

43 Guarner F, Guarner C, Prieto J, et al. Increased synthesis of systemic pros-

44 Moore K, Ward P, Taylor G, et al. Systemic and renal production of thromboxane A2 and prostacyclin in decompensated liver disease and hepatorenal syndrome. Gastroenterology 1991;100:1069-77.

45 Bruix J, Bosch J, Kravetz D, et al. Effects of prostaglandin inhibition on systemic and hepatic hemodynamics in patients with cirrhosis of the liver. Gastroenterology 1985;88:430-5.

46 Moreau R, Komeichi H, Kirstetter P, et al. Altered control of vascular tone by adenosine triphosphate sensitive potassium channels in rats with cirrhosis. Gastroenterology 1994;106:1016-23.

47 Moreau R, Komeichi H, Cailmail S, et al. Blockade of ATPsensitive K+ channels by glibenclamide reduces portal pressure and hyperkinetic circu-
lation in portal hypertensive rats. F Hepatol 1992;16:215-18.

48 Moreau R, Lebrec D. Endogenous factors involved in the control of arterial tone in cirrhosis. F Hepatol 1995;22:370-6.

49 Triger DR. Endotoxemia in liver disease-time for re-appraisal? $f$ Hepatol 1991;12:136-8.

50 Wilkinson SP, Moodie H, Stamatakis JD, et al. Endotoxaemia and renal failure in cirrhosis and obstructive jaundice. BMF 1976;2:141-58

51 Bourgoignie JJ, Valle GA. Endotoxin and renal dysfunction in liver disease. In: Epstein M, ed. The kidney in liver diseases. Baltimore: Williams and Wilkins, 1988:486-507.

52 Lumsden AB, Henderson JM, Kutner MH. Endotoxin levels measured by a chromogenic assay in portal hepatic and peripheral venous blood in chromogenic assay in portal hepatic and perip
patients with cirrhosis. Hepatology 1988; 8:232-6.

53 Sheron N, Bird G, Koskinas J, et al. Circulating and tissue levels of the neutrophil chemotaxin interleukin 8 are elevated in severe acute alcoholic hepatitis, and tissue levels correlate with neutrophil infiltration. Hepatology
1993;18:41-6.

54 Sheron N, Bird G, Goka J, et al. Elevated plasma interleukin6 and increased severity and mortality in alcoholic hepatitis. Clin Exp Immunol 1991;84: $449-53$.

55 Fernando B, Marley R, Holt S, et al. Acetylcysteine prevents development of the hyperdynamic circulation in the portal hypertensive rat. Hepatology 1998;28:689-94.

56 Lopez-Talavera JC, Levitzki A, Martinez M, et al. Tyrosine kinase inhibition ameliorates the hyperdynamic state and decreases nitric oxide production in cirrhotic rats with portal hypertension and ascites. 7 Clin Invest 1997;100:664-70.

57 LopezTalavera JC, Merrill WW, Groszmann RJ. Tumor necrosis factor alpha: a major contributor to the hyperdynamic circulation in prehepatic portal hypertensive rats. Gastroenterology 1995;108:761-7.

58 Pak JM, Lee SS. Review: glucagon in portal hypertension. $f$ Hepatol 1994;20:825-32.

59 Hirokawa K, O'Shaughnessy K, Moore K, et al. Induction of nitric oxide synthase in cultured vascular smooth muscle cells: the role of cyclic AMP. Br F Pharmacol 1994;112:396-402.

60 Wilkinson SP, Williams R. Renin-angiotensin-aldosterone system in cirrhosis. Gut $1980 ; 21: 545-54$.

61 Schroeder ET, Eich RH, Smulyan H, et al. Plasma renin level in hepatic cirrhosis: Relation to functional renal failure. Am 7 Med 1970;49:189-91.

62 Laragh JH, Cannon PJ, Bentzel CJ, et al. Angiotensin II, norepinephrine and renal transport of electrolytes and water in normal man and in cirrhosis with ascites. F Clin Invest 1963;42:1179-92.

63 Cobden I, Shore A, Wilkinson R, et al. Captopril in the hepatorenal syndrome. F Clin Gastroenterol 1985;7:354-60.

64 Gentilini P, Romanelli RG, La Villa G, et al. Effects of low dose captopril on renal hemodynamics and function in patients with cirrhosis of the liver. Gastroenterology 1993;104:588-94

65 Pariente EA, Bataille C, Bercoff E, et al. Acute effects of captopril on systemic and renal hemodynamics and renal function in cirrhotic patients with ascites. Gastroenterology 1985;88:1255-9.

66 Wood LJ, Goergen S, Stockigt JR, et al. Adverse effects of captopril in treatment of resistant ascites,

67 Schroeder ET, Anderson GH. Effect of blockade of angiotensin II on blood pressure, renin and aldosterone in cirrhosis. Kidney Int 1976;9:511-19.

68 Schneider AW, Kalk FJ, Klein CP. Effect of losartan, an angiotensin II receptor antagonist on portal pressure in cirrhosis. Hepatology 1999;29:

69 Debernardi-Venon D, Barletti C, Marzano A, et al. Efficacy of irbestartan, an angiotensin II receptor selective antagonist, in the treatment of portal hypertension. Hepatology 1999;30:219A.

70 Garcia-Tsao G. Angiotensin II receptor antagonist in the pharmacological therapy: a caution. Gastroenterology 1999;117:740-2.

71 Epstein M, Weitzman RE, Preston S, et al. Relationship between plasma arginine vasopressin and renal water handling in decompensated cirrhosis. Miner Electrolyte Metab 1984;10:165.

72 Bichet D, Szatalawicz W, Chaimovitz C, et al. Role of vasopressin in abnormal water excretion in cirrhosis patients. Ann Intern Med 1982;96:413-17.

73 Clària J, Jiménez W, Arroyo V, et al. Effect of V1-vasopressin receptor blockade on arterial pressure in conscious rats with cirrhosis and ascites. Gastroenterology 1991;100:494-501.

74 Epstein M. Renal prostaglandins and the control of renal function in liver disease. Am f Med 1986;80:46-61.

75 Guarner C, Colina I, Guarner F, et al. Renal prostaglandins in cirrhosis of the liver. Clin Sci 1986;70:477-84

76 Laffi G, La Villa G, Pinzani M, et al. Altered renal and platelet arachidonic acid metabolism in cirrhosis. Gastroenterology 1986;90:274-82

77 Rimola A, Gines P, Arroyo V, et al. Urinary excretion of 6-ketoprostaglandin F1alpha, thromboxane B2 and prostaglandin E2 in cirrhosis with ascites: relationship to functional renal failure (hepatorenal syndrome). F Hepatol 1986;3:111-17.

78 Zipser R, Hoefs J, Speckart P, et al. Prostaglandins: modulators of renal function and pressor resistance in chronic liver disease. 7 Clin Endocrinol Metab 1979;48:895-900.

79 Boyer T, Zia P, Reynold T. Effect of indomethacin and prostaglandin A, on renal function and plasma renin activity in alcoholic liver disease. Gastroenterology 1979;77:215-22.

80 Henriksen JH. Hepatorenal disorders: role of the sympathetic nervous system. Semin Liver Dis 1994;14:35-43.
81 Nicholls KM, Shapiro MD, Van Putten VJ, et al. Elelevated plasma norepinephrine concentrations in decompensated cirrhosis. Association with increased secretion rates, normal clearance rates, and suppressibility with increased secretion rates, normal clearance rates, and supp
by control of blood volume expansion. Circ Res 1985;56:457-61.

82 Zambraski EJ, DiBona GF. Sympathetic nervous system in hepatic cirrhosis. In: Epstein $\mathrm{M}$, ed. The kidney in liver diseases. Baltimore: Williams and Wilkins, 1988:469-85

83 Bichet DG, Van Putten VJ, Schrier RW. Potential role of increased sympathetic activity in impaired sodium and water excretion in cirrhosis. $N$ Engl f Med 1982;307:1552-7.

84 Gaudin C, Braillon A, Poo JL, et al. Regional sympathetic activity, severity of liver disease and hemodynamics in patients with cirrhosis. $\mathcal{f}$ Hepatol 1991;13:161-8.

85 Henriksen JH, Ring-Larsen H, Christensen NJ. Kidney, lower limb, and whole-body uptake and release of catecholamines in alcoholic liver disease. Clin Physiol 1988;8:203-10.

86 Henriksen JH, Christensen NJ, Ring-Larsen H. Noradrenaline and adrenaline concentrations in various vascular beds in patients witnh cirrhosis. Relation to haemodynamics. Clin Physiol 1981;1:293-304.

87 Kostreva D, Castaner A, Kampine J. Reflex effects of hepatic baroreceptors on renal and cardiac sympathetic nerve activity. Am F Physiol 1980;238: R390-4.

88 Levy $M$, Wexler MJ. Hepatic denervation alters first-phase urinary sodium excretion in dogs with cirrhosis. Am f Physiol 1987;253:F664-71.

89 Lang F, Tschernko E, Schulze E, et al. Hepatorenal reflex regulating kidney function. Hepatology 1991;14:590-4.

90 Jalan R, Forrest EH, Redhead DN, et al. Reduction in renal blood flow with acute increase of portal pressure gradient. Evidence for the hepatorenal reflex in man? Gut 1997;40:664-70

91 Solis-Herruzo JA, Duran A, Favelza V, et al. Effects of lumbar sympathetic block on kidney function in cirrhotic patients with hepatorenal syndrome. $\mathcal{F}$ Hepatol 1987;5:167-73

92 Ring-Larsen H, Palazzo U. Renal failure in fulminant hepatic failure and terminal cirrhosis: a comparison between incidence, types, and prognosis. Gut 1981;22:585-91.

93 Moller S, Emmeluth C, Henriksen JH. Elevated circulating plasma endothelin-1 concentrations in cirrhosis. F Hepatol 1993;19:285-90.

94 Uchihara M, Izumi N, Sato C, et al. Clinical significance of elevated plasma endothelin concentration in patients with cirrhosis. Hepatology 1992;16:95-

95 Moore K, Wendon J, Frazer M, et al. Plasma endothelin immunoreactivity in liver disease and the hepatorenal syndrome. N Engl F Med 1992;327:1774-8.

96 Brensing KA, Textor J, Perz J, et al. Long term outcome after transjugular intrahepatic portosystemic stent-shunt in non-transplant cirrhotics with hepatorenal syndrome: a phase II study. Gut 2000;47:288-95.

97 Asbert M, Gines A, Gines P, et al. Circulating levels of endothelin in cirrhosis. Gastroenterology 1993;104:1485-91.

98 Salo J, Francitorra A, Follo A, et al. Increased plasma endothelin in cirrhosis. Relationship with systemic endotoxemia and response to changes in effective blood volume. ₹ Hepatol 1995;22:389-98.

99 Morrow JD, Moore KP, Awad JA, et al. Marked overproduction of non-cyclooxygenase derives prostanoids (F2-isoprostanes) in the hepatorenon-cyclooxygenase derives prostanoids (F2-1.

100 Boulanger CM, Tanner FC, Bea ML, et al. Oxidized low density lipoproteins induce mRNA expression and release of endothelin from human and porcine endothelium. Circ Res 1992;70:1191-7.

101 Moore KP, Taylor GW, Gove C, et al. Synthesis and metabolism of cysteinyl leukotrienes by the isolated pig kidney. Kidney Int 1992;41:1543-8.

102 Moore KP, Taylor GW, Maltby NH, et al. Increased production of cysteinyl leukotrienes in hepatorenal syndrome. F Hepatol 1990;11:263-71.

103 Uemura M, Buchholz U, Kojima $\mathrm{H}$, et al. Cysteinyl leukotrienes in the urine of patients with liver diseases. Hepatology 1994;20:804-12.

104 Huber M, Kastner S, Scholmerich J, et al. Analysis of cysteinyl leukotrienes in human urine: enhanced excretion in patients with liver cirrhosis and hepatorenal syndrome. Eur f Clin Invest 1989;19:53-60.

105 Zipser RD, Radvan GH, Kronborg IJ, et al. Urinary thromboxane B2 and prostaglandin E2 in the hepatorenal syndrome: evidence for increased vasoconstrictor and decreased vasodilator factors. Gastroenterology 1983;84: 697-703.

106 Zipser RD, Kronborg I, Rector W, et al. Therapeutic trial of thromboxane synthesis inhibition in the hepatorenal syndrome. Gastroenterology 1984;87: 1228-32

107 Gines P, Rimola A, Planas R, et al. Norfloxacin prevents spontaneous bacterial peritonitis recurrence in cirrhosis: results of a double blind, placebocontrolled trial. Hepatology 1990;12:716-24.

108 Follo A, Llovet JM, Navasa M, et al. Renal impairment after spontaneous bacterial peritonitis in cirrhosis: predictive factors of infection resolution and survival in patients with cefotaxime. Hepatology 1994;20:1495-1501.

109 Sort P, Navasa M, Arroyo V, et al. Effect of intravenous albumin on renal impairment and mortality in patients with cirrhosis and spontaneous bacterial peritonitis. $N$ Engl $\mathcal{F}$ Med 1999;341:403-9.

110 Gines P, Tito L, Arroyo V, et al. Randomized compartive study of therapeutic paracentesis with and without intravenous albumin in cirrhosis. Gastroenterology 1988;84:1493-502.

111 Gines P, Fernandez-Esparrach G, Monescillo A, et al. Randomized trial comparing albumin, dextran 70 , and polygeline in cirrhotic patients with ascites treated by paracentesis. Gastroenterology 1996;111:1002-10.

112 Gines P, Arroyo V. Is there still a need for albumin infusions to treat patients with liver disease? Gut 2000;46:588-90.

113 Cabrera J, Arroyo V, Ballesta AM, et al. Aminoglycoside toxicity in cirrhosis. Value of urinary beta- 2 microglobulin to discriminate functional renal failure from acute tubular damage. Gastroenterology 1982;82:97-105.

114 Hadengue A, Moreau R, Gaudin C, et al. Total effective vascular compliance in patients with cirrhosis: a study of the response to acute blood volume expansion. Hepatology 1992;15:809-15.

115 Guevara M, Gines P, Fernandez-Esparrach G, et al. Reversibility of hepatorenal syndrome by prolonged administration of ornipressin and plasma volume expansion. Hepatology 1998;27:35-41.

116 Uriz J, Cardenas A, Sort P, et al. Telipressin plus albumin infusion: an effective and safe therapy of hepatorenal syndrome. F Hepatol 2000;33:43-8.

117 Navasa M, Follo A, Jimenez W, et al. Tumor necrosis factor and interleukin-6 in spontaneous bacterial peritonitis in cirrhosis: relationship with the development of renal imapirment and mortality. Hepatology 1998; 27:1227-32. 
118 Lenz K, Hortnagl H, Druml W, et al. Ornipressin in the treatment of functional renal failure in decompensated liver cirrhosis. Gastroenterology 1991; 101:1060-7.

119 Bennett WM, Keefe E, Melnyk K, et al. Response to dopamine hydrochloride in the hepatorenal syndrome. Arch Intern Med 1975;135:964-71.

120 Salo J, Gines A, Quer JC, et al. Renal and neurohormonal changes following simultaneous administration of systemic vasoconstrictors and dopamine or prostacyclin in cirrhotic patients with hepatorenal syndrome. f Hepatol 1996;25:916-23.

121 Gentilini P. Hepatorenal syndrome and ascites - an introduction. Liver 1999;19(suppl):5-14.

122 Hadengue A, Gadano A, Moreau R, et al. Beneficial effects of the 2-day administration of terlipressin in patients with cirrhosis and hepatorenal syndrome. F Hepatol 1998;29:565-70.

123 Angeli P, Volpin R, Piovan D, et al. Acute effects of the oral administration of midodrine, an alpha-adrenergic agonist, on renal hemodynamics and renal function in cirrhotic patients with ascites. Hepatology 1998;28:93743.

124 Fevery J, Van Cutsem E, Nevens F, et al. Reversal of hepatorenal syndrome in four patients by peroral misoprostol (prostaglandin E1 analogue) and albumin administration. f Hepatol 1990;11:153-8.
125 Gines A, Salmeron JM, Gines P, et al. Oral misoprostol or intravenous prostaglandin E2 do not improve renal function in patients with cirrhosis and ascites with hyponatremia or renal failure. 7 Hepatol 1993;17:220-6.

126 Moore K, Wendon J, Frazer M, et al. Plasma endothelin immunoreactivity in liver disease and the hepatorenal syndrome. $N$ Engl $f \mathrm{Med}$

127 Soper CP, Latif AB, Bending MR. Amelioration of hepatorenal syndrome with selective endothelin-A antagonist. Lancet 1996;347:1842-3.

128 Holt S, Marley R, Fernando B, et al. Improvement of renal function in hepatorenal syndrome with N-acetyl cysteine. Lancet 1999;353:294

129 Mitzner S, Stange J, Klammt S, et al. Improvement of hepatorenal syndrome with extracorporeal albumin dialysis MARS: results of a prospective, randomized, controlled trial. Liver Transplant 2000;6:277-86.

130 Brensing KA, Textor J, Strunk H, et al. Transjugular intrahepatic portosystemic stent-shunt for hepatorenal syndrome. Lancet 1997;349:697-8.

131 Gonwa TA, Morris CA, Goldstein RM, et al. Long-term survival and renal function following liver transplantation in patients with and without hepatorenal syndrome-experience in 300 patients. Transplantation 1991;51: torenal s.8

132 Le Moine O. Hepatorenal syndrome-outcome after liver transplantation. Nephrol Dial Transplant 1998;13:20-2.

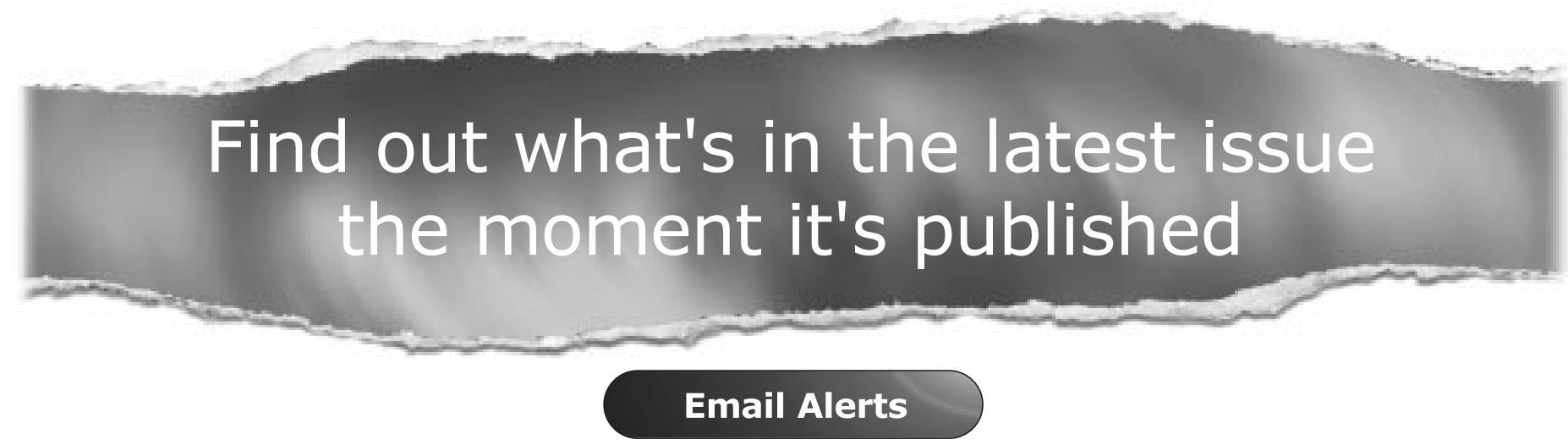

Sign up to receive the table of contents by email every month. You can select from three alerts: Table of Contents (full), TOC Awareness (notice only); Gut related announcements.

www.gutjnl.com 